\title{
Heat Induced Changes of Peda as Determined by Microstructure and Texture
}

\author{
Sumita Das ${ }^{1}$, , A. K. Bandyopadhyay ${ }^{2}$ and P. K. Ghatak ${ }^{2}$ \\ ${ }^{1}$ Department of Food Technology, Haldia Institute of Technology, Haldia \\ Purba Medinipur, West Bengal, India - 721657 \\ ${ }^{2}$ Department of Dairy Chemistry, West Bengal University of Animal \& Fishery Sciences \\ Mohanpur Campus, Nadia, West Bengal, India - 741252 \\ *Corresponding author's email: sumitadas.dt [AT] gmail.com
}

\begin{abstract}
Scanning Electron Microscopy (SEM) was used to study the relationship between submicroscopic structure and macroscopic properties occurred during processing of peda, a popular heat desiccated Indian dairy confection. Various components of milk undergo complex interaction amongst themselves due to prolonged heat treatment and with the added sugar molecules. An investigation was therefore carried out to study the sub-microstructure of peda to determine the internal structure and better understanding of the typical body \& texture of this traditional Indian sweet delicacy. The microstructure of peda reveals that the extensive heat treatment causes formation of caseinwhey protein complexes which ultimately fused with lactose and sugar. The coalesced protein agglomerated as thick bridges. Large aggregates of lactose crystals and more void space was found in market peda which might be due to ununiform kneading during processing. The textural properties differed markedly in laboratory and market peda. High hardness, fracturability, gumminess and chewiness and low springiness and cohesiveness of market peda might be due to extensive heating and lack of compactness. It was evident from SEM that the compactness of the network in market peda was lower as compared to laboratory samples and presence of scale or layer type structure in market samples indicated overheating of the product.
\end{abstract}

Keywords - Scanning electron microscope, microstructure, textural properties, compactness

\section{INTRODUCTION}

India is the largest milk producing country in the World with about 132.8 million tones milk production annually (Puri and Geevarghese, 2015). Lack of appropriate cooling facilities to keep liquid milk fresh in warm climate and high cost of converting it into other milk products lead to the diversion of milk for preparation of different indigenous milk products with comparatively longer shelf life. About $50-55 \%$ of total milk produced in the country is converted into various traditional dairy products with strong social and cultural heritage in the Indian society (Bhasin, 2010; Prasad et al., 2012; Jain et al., 2015). The quantity of peda produced in India far exceeds any other indigenous milk based sweets (Mahadevan, 1991). Peda which is mostly consumed as religious 'prasad' in temples is a popular traditional sweetmeat of central and Northern India and to a lesser extent in Western and Eastern regions also. It is prepared by heat desiccation of a mixture of concentrated milk solids (khoa) and sugar to a homogeneous consistency and characterized by reddish brown color due to caramelization of sucrose during processing. Commercially sold peda varies widely in color, body, texture, sweetness, taste and flavor. Different types of peda are developed over a period of time throughout the country like white peda, yellow peda, brown peda, kesar peda and some regional variants namely, Mathura peda, Kunthalgiri peda, Dharwad peda, lal peda and bal mithai etc. Depending on manufacturing techniques, type and quality of raw materials used, additives, individual skills and consumers preferences peda samples vary widely in the physico-chemical, rheological and sensory properties (Patel et al., 2011).

The interest of researchers and the manufacturers in the structure of various milk products has been growing as it is recognized that there are definite co-relationship between the structure and texture as well as other physical properties of the products. During various technological treatments the milk constituents viz. fat globules, casein whey proteins, lactose etc. undergo significant physical changes and mutual interactions. This leads to the development of characteristic microstructure 
and physical properties of the products. The vigorous heat treatment of milk and addition of sugar during manufacturing of peda are believed to accompany some structural rearrangements in the product which can be studied by light microscopy and electron microscopy. Texture is an important quality attribute in peda which decides its ultimate acceptance by the consumers. The textural characteristics of peda are greatly influenced by its composition, type \& quality of raw material used and manufacturing parameters followed. Texture can be measured by means of intrinsic sensory evaluation as well as instrumental tests. A wide variation is noticed amongst different judges during sensory evaluation. Hence rheological properties enumerated by instrumental techniques are used for better representation of textural properties. Texture profile analysis (TPA) comprises a two-bite test that gives textural properties of food products in terms of hardness, adhesiveness, cohesiveness, springiness and gumminess (Bourne, 2002). In TPA, hardness refers to the force required to compress the food whereas fracturability is the force required for breaking foods into pieces after compressing it (Larmond, 1976). Cohesiveness refers to the degree to which a substance is compressed between the teeth before it breaks which can be measured instrumentally by calculating the ratio of the area of second bite to that of first bite (Larmond, 1976; Bourne, 2002). Springiness refers to the height that the sample recovers during force relaxation time between first and second bite compression cycle (Patel et al., 2011). Gumminess can be defined as the energy required for disintegrating a semi-solid food to a state ready for swallowing (Larmond, 1976). Chewiness refers to the energy required to masticate food into a state ready for swallowing and is a product of hardness, cohesiveness and springiness (Patel et al., 2011).

The various components of milk undergo complex interaction amongst themselves due to heat treatment and with the added sugar during manufacturing of peda. It is important to know how the heat induced changes affect the internal structure and texture of these products. This investigation was therefore, undertaken to study the sub-microstructure as well as texture profile analysis of peda for better understanding of the typical body and texture of this traditional delicacy of India.

\section{MATERIALS AND METHODS}

\subsection{Materials}

Cow milk and cane sugar was purchased from local market of Kolkata. Peda samples were also collected from local markets to compare their micro structure and texture with laboratory made peda samples. All the chemicals used were of analytical grade and purchased from HIMEDIA ${ }^{\circledR}$.

\subsection{Manufacturing of Peda}

Peda was prepared in the laboratory by heat desiccation of standardized cow milk (4.5\% fat and $8.5 \%$ SNF) with addition of $8 \%$ cane sugar on the basis of milk as per the method described by Dharampal (1998).

\subsection{Scanning Electron Microscopic Study}

The scanning electron microscopic (SEM) study was carried out following the method laid out by Kalab et al. (1988) with certain modifications. First, the peda samples were taken from beneath the surface and cut into small pieces of $1 \times 1 \times 5$ $\mathrm{mm}^{3}$ size with sharp blades. The samples were fixed in $2.8 \%$ glutaraldehyde solution to stabilize protein matrix and facilitate removal of solute constituents followed by thorough washing in phosphate buffer of $\mathrm{pH}$ 7.3. This was followed by post fixation with $2 \%$ osmium tetroxide $\left(\mathrm{OsO}_{4}\right)$ solution and washing with $0.135(\mathrm{M})$ phosphate buffer to stabilize and fix fat. Then the aqueous phase was replaced with a cryoprotective media of absolute alcohol by dehydrating the sample with a series of ethyl alcohol viz. 50\%, 60\%, 70\%, 80\%, 90\% and 100\% for 30 minute each followed by defatting in chloroform. The samples were then put into a freeze fracturing tube and fractured with a sharp knife under liquid nitrogen to expose the undamaged interior. It was then taken back to absolute ethanol of critical point drying at $30^{\circ} \mathrm{C}$ slightly below atmospheric pressure. Starch, if present in the sample may get shrunken here. The samples were then fixed on a metal slab with adhesive and dried. The samples were then uniformly coated with gold (thickness $\geq 20 \mathrm{~mm}$ ) in an ion coater (Model: GIKOIB - 3, Japan) under 0.1 torr vacuum for 5 minute at an ion current of $6 \mathrm{mV}$ for rendering the sample electrically conductive. The gold coated samples were then taken under an electron microscope (Hitachi, Model No: S - 405, Japan) and scanned at 20 $\mathrm{kV}$ at different magnification for the desired microstructure. When the desired field has achieved a photographic reversal was done like common photographs and the micrographs were taken for further detailed study.

\subsection{Texture profile analysis}

A Texture Analyzer (Model: TAHDi, Stable Micro System, UK) fitted with a $250 \mathrm{~kg}$ load cell was used for two bites linear compression of peda samples. A cross head pretest speed of $2 \mathrm{~mm} / \mathrm{s}$, test speed of $5 \mathrm{~mm} / \mathrm{s}$, post-test speed of $5 \mathrm{~mm} / \mathrm{s}$ and interval of $5 \mathrm{~s}$ between two successive bites were employed for $50 \%$ compression of the samples. The sample was cut into $1 \mathrm{~cm}^{3}$ size pieces and temperature of the sample was maintained at $25^{\circ} \mathrm{C}$ during texture analysis. A cylindrical probe of 
$75 \mathrm{~mm}$ diameter was used for textural study. The texture analyzer having separate software (Texture Expert) for its operation was run under Windows environment to get the Texture Profile Analysis (TPA) data from the measurements. The hardness, fracturability and adhesiveness were directly calculated from Force-Time curve while other parameters like springiness, cohesiveness, gumminess and chewiness were obtained directly from the Microprocessor.

\subsection{Statistical analysis}

All the data were expressed as mean \pm standard deviation of mean calculated from five independent experiments for laboratory made samples and ten for market samples. Pair comparison t-test was carried out to measure the test for significance as described by Snedecor and Cochran (1994).

\section{RESULTS AND DISCUSSIONS}

\subsection{Microstructure of Peda}

From the figure 1 (i), which represents the scanning electron micrograph of laboratory made peda at lower magnification where the bar length is $50 \mu \mathrm{m}$, it has been observed that the surface was compact and uneven and obscured with fat. The granules of heat coagulated proteins coalesces together to form the compact protein matrix with numerous small pores. The intergranular spaces were filled with milk serum and fat. Some sort of thermal degradation took place in the casein whey protein complexes which ultimately fused with lactose and sugar. Small lactose crystals were also found. The microstructure of the same peda samples at higher magnification was represented in figure 1 (ii) where the scale length is $10 \mu \mathrm{m}$. In this picture the coalesced protein agglomerates with thick bridges are clearly noticed along with some small lactose crystals and void spaces. The array of conglomerated mass of protein showed no particular orientation. The heat fusion of protein with lactose and sugar were so strong that not a single casein micelle has restored its subunit size.



(i)



(ii)

Fig. 1: SEM image of laboratory made peda samples

Figure 2 (i) represents the SEM of market peda samples at lower magnification which shows somehow different protein network to that of laboratory peda samples. Here the protein matrix revealed agglomerated uneven protein particles joined irregularly to form thick bridges. The agglomerated protein matrix interlinked strongly forming a compact scale or layer type structure. The size of lactose crystal and fat globules in inter granular spaces were larger as compared to the laboratory made samples. The ultrastructure of market peda samples at higher magnification has been represented in figure2 (ii). It shows coalesced ragged protein matrix linked together into thick compact bridges. Thick thread like micelles is arranged in a regular and folded manner. However, these casein agglomerates fused densely together forming a layer or scale type structure. 


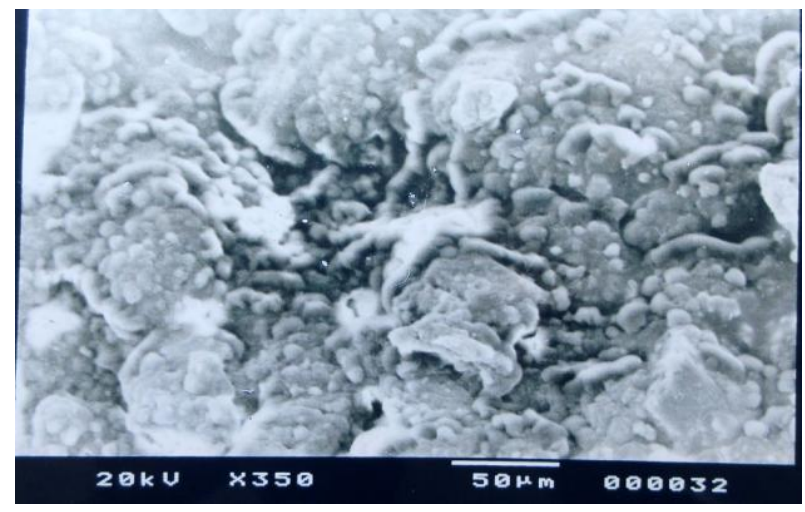

(i)



(ii)

Fig. 2: SEM image of market peda samples

Patil et al., 1992 studied the microstructure of khoa. They reported that khoa has a granular texture consisting of protein granules with several hundred of micrometers in diameter. The granules consist of intact and partially fused casein micelles and non micellar protein along with condensed milk serum and fat filling the intergranular spaces. Large aggregate of lactose crystals developed in inter granular space in the unworked khoa during storage and the sandiness in the stored product was markedly increased. Working of khoa reduced the dimensions of protein granules and intergranular void spaces and produced large amounts of fat globule membrane fragments liberating free fat. They also reported that individual lactose crystals in worked khoa stored at $20^{\circ} \mathrm{C}$ for 48 hours were more uniformly distributed compared to unworked khoa. Storage did not increase the sandiness in worked khoa.

\subsection{Texture Profile Analysis of Peda}

The TPA of laboratory made as well as market peda samples was depicted in Table 1. From the table it was clear that hardness, fracturability, gumminess and chewiness of market peda samples were considerably higher than those of laboratory made samples. However, a lower cohesiveness and higher springiness values were also noticed in most of the market samples. These differences might be due to the use of different types of milk as well as manufacturing conditions in various shops. These findings are almost similar to the work of Gupta et al., (1990) and Patel et al. (1990) who reported the increased hardness, gumminess, chewiness and decreased cohesiveness in khoa samples were directly related to its total solids content. They further stated that working of khoa significantly decreased the hardness and springiness but increased cohesiveness. The work of Gupta et al. (1990) and Adhikari et al. (1994) revealed that springiness was the only textural attribute which had no correlation with any of the compositional parameters of khoa. The springiness was directly related to the porosity of the product (Jha et al., 2014).

Table 1: Texture profile analysis of peda samples

\begin{tabular}{c|cc|cc}
\hline \multirow{2}{*}{ Texture properties } & \multicolumn{2}{|c|}{ Laboratory made peda $\boldsymbol{a}^{\mathbf{a}}$} & \multicolumn{2}{c}{ Market peda $^{\mathbf{b}}$} \\
& Range & Average & Range & Average \\
\hline Hardness (kg) & $49.19-63.54$ & $55.10 \pm 1.04$ & $77.03-248.15$ & $152.02 \pm 34.84$ \\
Fracturability (kg) & $0.0345-0.0374$ & $0.0359 \pm 0.002$ & $5.36-39.63$ & $20.61 \pm 11.38$ \\
Springiness (mm) & $0.269-0.278$ & $0.272 \pm 0.002$ & $0.225-0.349$ & $0.282 \pm 0.04$ \\
Cohesiveness (mm) & $0.201-0.254$ & $0.228 \pm 0.011$ & $0.073-0.398$ & $0.196-0.04$ \\
Gumminess (kg) & $9.87-14.76$ & $11.18 \pm 0.91$ & $5.60-98.85$ & $43.31 \pm 21.13$ \\
Chewiness (kg-m) & $0.0026-0.0045$ & $0.0034 \pm 0.0002$ & $0.0019-0.0223$ & $0.0121 \pm 0.006$ \\
\hline
\end{tabular}

${ }^{\text {a }}$ Average of five samples

${ }^{\mathrm{b}}$ Average of ten sample

A statistical analysis was also carried out by pair comparison $\mathrm{t}$ - test to determine the level of significance among various textural parameters (Table: 2). The hardness, fracturability, gumminess and chewiness of laboratory made peda samples and 
hardness and fracturability of market samples were significant at $5 \%(\mathrm{p}<0.05)$ level. On the other hand, cohesiveness of lab samples and gumminess and chewiness of market peda samples were highly significant at $1 \%(\mathrm{p}<0.01)$ level. The springiness of both peda samples and cohesiveness of market peda were found to be non significant.

Table 2: $\mathrm{t}$ - Test for texture profile of peda samples

\begin{tabular}{|c|c|c|c|c|c|c|c|c|}
\hline \multirow[t]{2}{*}{ Samples } & \multirow[t]{2}{*}{$\mathrm{df}$} & \multicolumn{6}{|c|}{ Observed $\mathrm{t}$ - value } & \multirow{2}{*}{$\begin{array}{c}\mathrm{t}- \\
\text { critica }\end{array}$} \\
\hline & & Hardness & Fracturability & Cohesiveness & Springiness & Gumminess & Chewiness & \\
\hline Lab & 4 & $5.866 * *$ & $5.007 * *$ & $1.918^{*}$ & 0.481 & $3.85^{* *}$ & $3.82 * *$ & 1.771 \\
\hline Market & 9 & $5.866 * *$ & $5.007 * *$ & 1.918 & 0.481 & $3.85^{*}$ & $3.82 *$ & 2.16 \\
\hline
\end{tabular}

* Significant at $5 \%(\mathrm{p}<0.05)$ level

** Significant at $1 \%(\mathrm{p}<0.01)$ level

The texture profile of different peda samples collected from Raipur city market was determined by Banjare et al., 2015 and from Varanasi market by Prasad et al., 2012 and compared them with laboratory made samples. All researchers reported significant differences in all textural parameters among different market samples as well as with laboratory made samples.

\section{CONCLUSION}

Characterization of various food products on the basis of their microstructure and texture forms the backbone of the scientific approach to process innovation and quality assurance in modern industrial practices. The current trends, round the globe, favours such studies to facilitate product description as well as specifications for promoting process control and for international trade. The scanning electron micrograph of laboratory made peda samples showed heat coagulated proteins coalesced together to form the compact protein matrix with small pores filling with milk serum, fat globules and small lactose crystals. Whereas the SEM of market peda samples showed coalesced, ragged protein matrix linked together in a compact thick bridge. The agglomerated protein matrix interlinked strongly forming compact scale or layer type structure. The size of lactose crystals and fat globules in the intergranular spaces were larger as compared to the laboratory made samples. From the SEM studies it can also be concluded that the lab samples were finely worked as compared to unworking of market peda. The presence of scale or layer type structure in the market samples indicated overheating of the product. From the texture profile analysis it can be concluded that market and laboratory made peda samples differ in textural parameters which is the result of using different types of milk, varying level of sugar, different moisture levels, processing conditions and individual skill.

\section{REFERENCES}

- $\quad$ Adhikari A.K, Mathur O.N and Patil G.R (1994). Interrelationships among Instron textural parameters, composition and microstructure of khoa and gulabjamun made from buffalo milk. Journal of Food Science and Technology, 31 (4), 279 - 284.

- Banjare K, Kumar M, Goel B.K and Uprit S (2015). Studies on Chemical, Textural and Sensory Characteristics of Market and Laboratory Peda Samples Manufactured in Raipur City of Chhattisgarh. Oriental Journal of Chemistry, 31(1), 231-238.

- Bhasin NR (2010). President's desk. Indian Dairyman, 62, 12-13.

- Bourn, M (2002). Food texture and viscosity: Concept and measurement. London: Elsevier Publishers Co., USA, (1976)

- Dharampal (1998). Technology of khoa based sweets, Advances in Traditional Dairy Products Lecture compendium of CAS short course held at NDRI, Karnal. Pp 31-35.

- Gupta S.K, Patil G.R, Patel A.A, Garg F.C and Rajorhia G.S (1990). Instron texture profile parameters of khoa as influenced by composition. Journal of Food Science and Technology, 27 (4), 209 - 213.

- Jain V, Rasane P, Jha A, Sharma N and Gautam A (2015). Effect of modified atmospheric packaging on the shelf life of Kalakand and its influence on microbial, textural, sensory and physico-chemical properties. Journal of Food Science \& Technology, 52(7), 4090-4101 
- Jha A, Kumar A, Jain P, Om H, Singh R and Bunkar D.S (2014). Physico-chemical and sensory changes during the storage of lal peda. Journal of Food Science and Technology, 51(6), 1173-1178.

- Kalab M, Gupta S.K, Desai H.K and Patil, G.R (1988). Development of microstructure in rae, fried and cooked paneer made from buffalo, cow and mixed milks. Food Microstructure, 7, 83-91.

- Larmond E (1976). Sensory measurement of food texture. In "Rheology and Texture in Food Quality". (Deman J.M; Voisey P.W; Rasper, V.F and Stanley D.W, Editors). AVI Publishing.

- Mahadevan A.L (1991). Nutritive value of traditional milk products. Proceedings of Workshop on Indigenous Milk Products held at National Dairy Development Board, Anand. January 15-19, pp. 62.

- $\quad$ Patel H.A, Salunke P and Thakar P.N (2011). International Journal of Dairy Foods. 1(1), 68-75.

- Patil G.R, Patel A.A, Allan-Wojtas P and Kalab M (1992). Microstructure and texture of khoa. Food Structure, 11, 155.

- Prasad R, Jha A and Jha A (2012). Textural and Sensory Characteristics of Market Samples of Peda Manufacture in Varanasi City of India. Journal of Dairying Foods and Home Science, 31(4), 239-243.

- Puri R.K and Geevarghese P.I (2015). Physico-Chemical, Sensory and Colour Analysis of Peda prepared using Caesalpinia sappan L. as Natural Colourant. International Journal on Applied Bioengineering, 9 (2), 7 - 10.

- Snedecor C.W and Cochran W.G (1994). Statistical Methods, 6th edn. Ames, IA, USA: Iowa State University. 